\title{
The Current Situation and Development of Fire Resistance Design for Steel Structures in China
}

\author{
Jincheng Zhao* and Xiuying Yang \\ Department of Civil Engineering, Shanghai Jiao Tong University, Shanghai, 200240, China
}

\begin{abstract}
A review of the current situation and development of fire safety design for steel structures in China is given in this paper. Several codes and specifications used for fire safety design in China are introduced, and the present design methods are summarized. Then some research achievements on the behavior of steel structures at elevated temperature are presented. The achievements include material properties of steel at high temperatures, finite element theoretical analysis and experimental research on steel structures and structural members, high-temperature behavior of beam-to-column joints, fire resistance of composite structures and structural members, and etc. From all of the content, the conclusion is drawn that the fire safety researches of steel structures need to be further carried out both theoretically and experimentally, although obvious works have been achieved.
\end{abstract}

Keywords: Steel structures, fire resistance design, building codes, specifications, research achievements.

\section{INTRODUCTION}

The steel structures have been used widely in China, and the fire resistant behavior of steel structures has drawn more attention, more and more researches have been carried out on fire safety design of steel structure, and many achievements have been obtained.

In China, there are several national building codes currently in use for fire protection or prevention design of different kinds of buildings, for instance, "Building code for fire protection design" (GB50016-2006), "Code for fire protection design of tall buildings" (GB50045-95), "Technical specification for steel structure of tall buildings" (JGJ 9998), "Technical specification for application of fire protection coating for steel structure" (CECS24-90). Most of them are mainly concerned with the active methods for fire prevention, while the technical code CECS 200: 2006 was specially developed for fire safety design of steel structures by advanced method, which is put in force since 2006.

\section{BUILDING CODES AND SPECIFICATION}

\section{1. "Building Code for Fire Protection Design" (GB50016-2006) [1]}

For fire safety design of buildings, the most commonly used building code is the "Building Code for fire protection design" (GB50016-2006) approved by former China's State Development Planning Commission in 1995.

In this building code, buildings are divided into four groups with different "fire resistance grade" according to the building's importance. For buildings with different "fire resistance grade", the fire duration requirement of structural or non-structural members is different. The list of the fire

Address correspondence to this author at the No. 800 Dong Chuan Road, Minhang, Dept. of Civil Engineering, Shanghai Jiao Tong University, Shanghai, P. R. China (postalcode:200240); Tel: +86-21-62932796; Fax: +86-21-34206334; E-mail: jczhao@sjtu.edu.cn duration requirement for different kinds of building members is given in this code, seen as Table $\mathbf{1}$.

According to the test results under ISO Standard 834, the fire resistance limit of various kinds of building members with different section sizes were roughly listed in appendix two of GB50016-2006.

It should be pointed out that the "Building Code for fire protection design" (GB50016-2006) is only valid for: (1) residential buildings with 9 or less stories and other civil buildings which are not taller than 24 meters or one-storey public buildings which are taller than 24 meters. (2) onestorey, multi-storey and high-rise industrial buildings.

\section{2. "Code for Fire Protection Design of Tall Buildings" (GB 50045-95) [2]}

For residential buildings with 10 stories or more than 10 stories and other civil buildings with a height of more than 24 meters, there is another national standard "Code for fire protection design of tall buildings" (GB 50045-95) approved by China's Ministry of Construction in 1995. In this building code, all of the tall buildings were divided into two general categories with different fire resistance grade. For each category, the code specified the fire duration requirement for different kinds of building members just being similar to those listed in Table $\mathbf{1}$.

For buildings with a height over 250 meters, special measures approved by related experts should be taken for fire safety design.

\section{3. "Technical Specification for Steel Structure of Tall Buildings" (JGJ 99-98) [3]}

In the national building code "code for design of steel structures" (GB 50017-2003), there are almost no items regarding the fire safety design. In 1998, the "Technical specification for steel structure of tall buildings" was issued. It 
Table 1. Combustion Behavior and Fire Duration Requirement for Different Kinds of Building Members

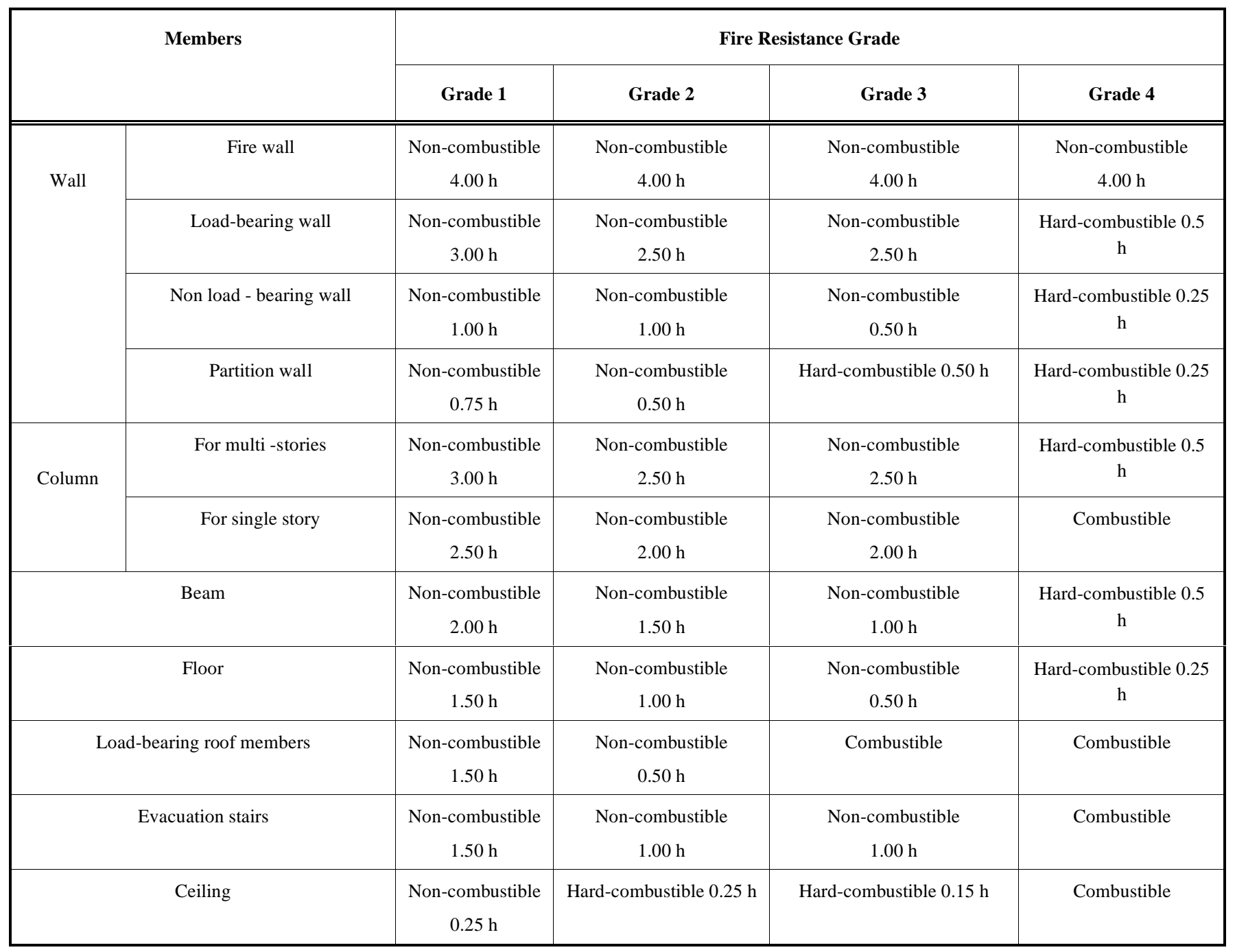

was edited by Chinese Institute of Building Technology and approved by China's Ministry of Construction.

In this specification, there is a specific chapter relating to fire protection of steel structures. Some recommendations are given in this chapter. First, the combustion behavior and fire duration requirement of building members are specified, they are roughly as same as those listed in Table $\mathbf{1}$ (only for buildings of grade one or two). Then suggestions for the selection of fire protection materials and for the calculation of the material thickness are made. In the third section of this chapter, construction details of fire protection methods for structural steel work - columns, beams, floor, and roof systems are specified respectively.

\section{4. "Technical Specification for Application of Fire Pro- tection Coating for Steel Structure" (CECS24-90) [4]}

Fire protection coatings are widely used for fire safety of steel structures in China. For this reason, in 1990, China's Association of Standardization for Engineering Construction issued a national standard "Technical specification for application of fire protection coating for steel structure".
In the specification, the fire protection coatings are classified into two categories by the thickness necessary for a certain period of fire duration: (a) thin-type coatings, with a thickness of not more than $7 \mathrm{~mm}$; (b) thick-type coatings, with a thickness from 8 to $50 \mathrm{~mm}$. The application of these two types of coatings should refer to the following items:

- For internal steel works thoroughly exposed, lightweight roof steel structures and any other kind of steel structures where decoration is needed, the thin-type fire protection coating is suitable if the fire duration requirement is 1.5 hour or less;

- For internal steel works hidden from view, high-rise steel structures and multi-storey industrial buildings in steel structure, the thick-type fire protection coating should be used if the fire duration requirement is more than 1.5 hour;

- For external steel work, appropriate fire protection coating should be used.

There are two ways to determine the thickness of the fire protection coating, one is test-based method, and another is calculation-based method. So the thickness of the fire protec- 
tion coating can be determined either by ISO Standard 834 test results or by calculation using the method specified in Appendix 3 of CECS24-90, seen as equation 1.

$T h_{1}=\left(W_{2} / D_{2}\right) /\left(W_{1} / D_{1}\right) \times T h_{2} \times K$

Equation 1 is valid when $W / D \geq 22, T h \geq 9 \mathrm{~mm}$ and the fire duration $t \geq 60$ minutes.

\section{5. "Technical Code for Fire Safety of Steel Structure in Buildings" (CECS 200:2006) [5]}

It can been seen from various building codes or specifications introduced above that the fire safety design of steel structures is mainly based upon ISO Standard 834 test of structural steel members. More clearly, some kind of fire protection materials (usually coatings, sometimes boards) must be applied to make the steel members meet the fire duration requirement specified by building codes or specifications. The thickness of fire protection materials covering steel members is determined according to fire test results or technical parameters provided by manufacturers which are also based on fire test results. Undoubtedly, this design method is relatively simple and convenient for engineers, but some inevitable drawbacks also exit in this method.

With the rapid development of the steel structure and the researches on its fire resistance behavior, it is necessary and timely to develop an alternative to replace the customary fire test-based method. Under this background, in the year of 2000 , a local recommended specification for fire safety design of structural steel buildings, "Technical code on fire safety of steel building structures" (DG/TJ08-008-2000), was approved and issued by "Shanghai Construction and Management Commission" in Shanghai. Although this recommended specification has not been widely adopted for the design of practical engineering yet, the trend of advanced design rules for fire safety engineering has been shown clearly and the achievements made by Chinese researchers during the last decade of the twentieth century have been reflected.

Based on the local specification (DG/TJ08-008-2000), another stylebook came into being in 2005 , which was sent to be censored by national related department, and then with a quantity of modification, a new technical code was approved by China's Association of Standardization for Engineering Construction. This technical code is named "Technical code for fire safety of steel structure in buildings", which was put in force since Aug 2006.

The remarkable highlight of the new technical code is that it introduces the analytical and calculational approach to the fire resistance design of steel structures. In addition to the general rules such as the fire resistance grade classification of structural steel buildings and the specifications of fire resistance requirements of steel members, which are as same as those provided in national building codes, there are four entirely new sections regarding the fire resistance analysis of steel structures.

In this code, temperature-effect on member is equivalent to loads adding to both ends of the member, shown as (Fig. 1), and then the temperature-induced internal force of the member in fire is calculated as equations 2 and 3.

$$
\begin{aligned}
& N_{T}=N_{T e}-N_{f} . \\
& M_{T i}=M_{T e}-M_{f i}
\end{aligned}
$$

Where

$$
\begin{aligned}
& N_{T e}=\alpha_{s} E_{T} A\left[\left(T_{1}+T_{2}\right) / 2-T_{0}\right] \\
& M_{T e}=E_{T} I / h \times \alpha_{s}\left(T_{2}-T_{1}\right)
\end{aligned}
$$
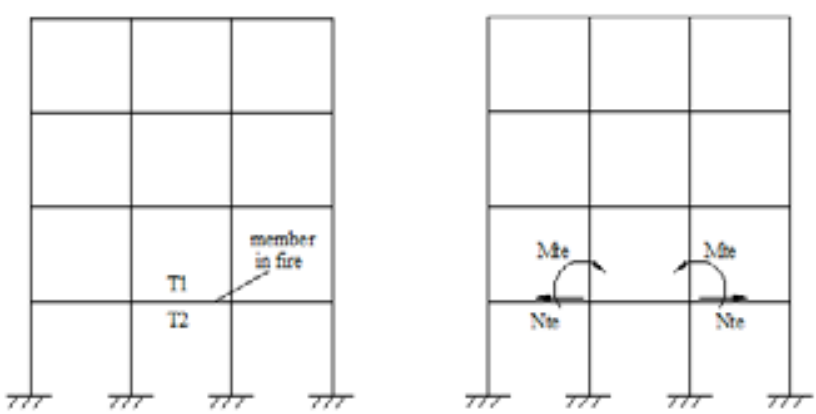

(a) temperature rising of member (b) equivalent loads

Fig. (1). The equivalent load of temperature-effect.

It should be noted that only the simple calculation model aiming at structural steel members is presented in the specification, more advanced calculation model based on fire resistance analysis of whole structure has been not involved yet.

\subsection{Present Design Status}

According to Chinese building codes, all industrial and civil buildings in steel structure should be protected from fire so as to meet the fire duration requirement specified by related codes or specifications. Generally, there are several methods commonly in use for fire protection nowadays in China, respectively they are:

- Coatings ( intumescent or non-intumescent ) protection

- Board protection

- Partially or completely encased in concrete

Among these methods, coatings protection is used most commonly for steel structures.

The procedure for fire safety design can be demonstrated by the flowing chart shown in Fig. (2).

It should be noted that the concept of performance-based fire safety design has been introduced to the practical engineering design, although there are no items or parts relating to this kind of design in the current building codes or specifications. For a long time in the past, fire safety design of building structures was prescription-based, the items or provisions in building codes or specifications must be strictly followed. This situation has become flexible in recent years, and the performance-based idea or concept has been reflected in the fire safety design of a series of large-span steel structures such as Shanghai Science and Technology Museum, Shanghai Pudong International Airport, Shanghai New International Exhibition Center, mainly in the following aspects: 


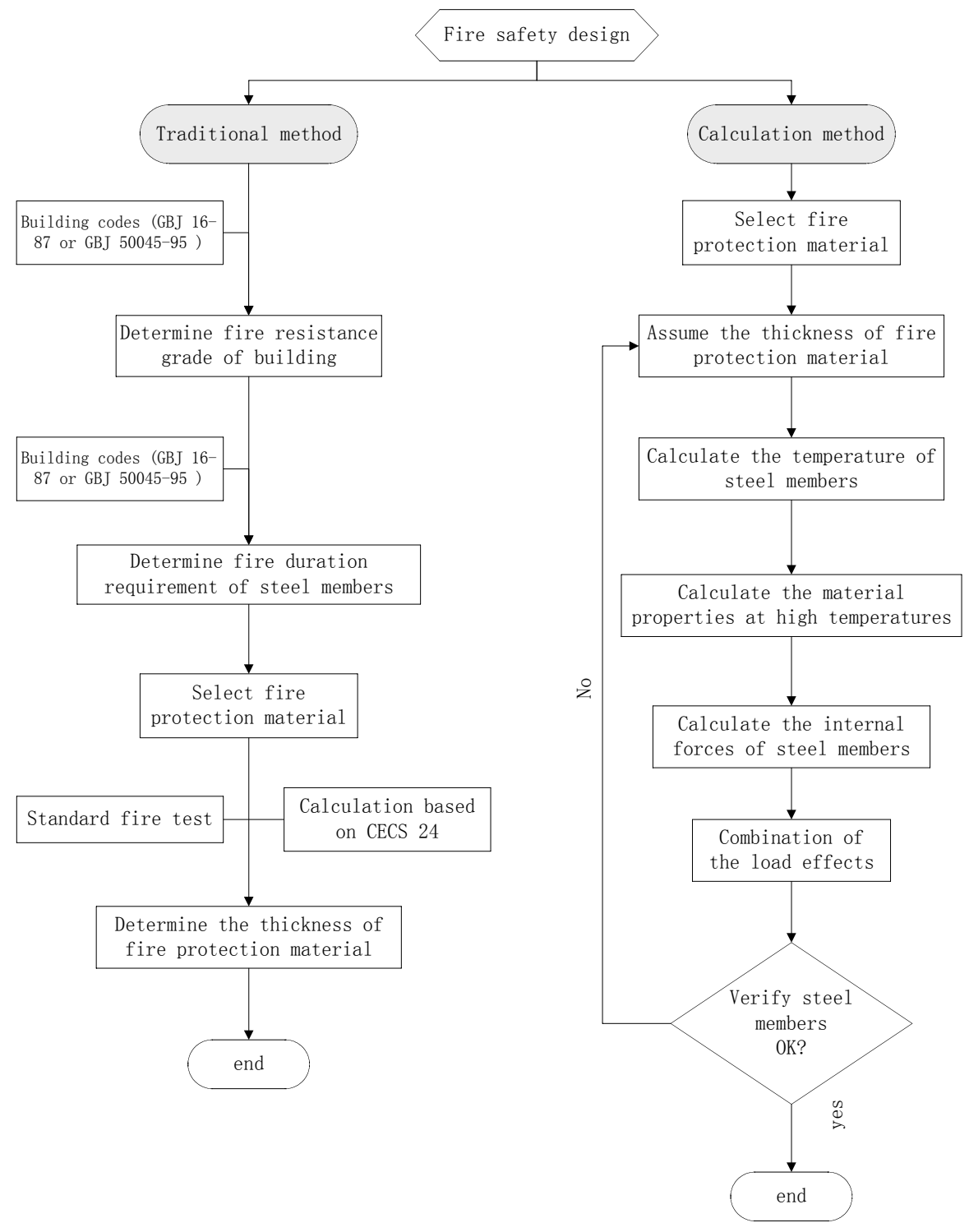

Fig. (2). Flowing chart for fire safety design of steel structures.

- Partition of fire zone: The largest area of a fire zone is limited to 5000 square meters by "Building Code for fire protection design" (GB50016-2006), this limitation has been widely surpassed where the fire action is not severe or the fire fatalness is not serious or some other effective measures have been taken.

- Some steel members are not protected against fire after deliberate consideration or calculation.

- The application of advanced analytical models for fire safety design: in the fire design of steel work of Shanghai New International Exhibition Center, the fire modeling software package FPETOOL 3.2 developed by NIST in the US was adopted. The design of sprinkler system referred to the NFPA (1996) standard as well.

\section{RESEARCH ACTIVITIES}

The research works on fire resistance behavior of steel structures started about in the end of 1980s in China. Since then, more than ten years had passed before considerable achievements were made in the following aspects:

\subsection{Material Properties of Steel at High Temperatures}

A series of high-temperature tests on structural steel Q235 and Q345, the most commonly used steel grades in China for building constructions, have been conducted in the past several years to research the mechanical and physical behavior of structural steel under fire conditions. Several models of steel material properties have been put forward for fire resistance analysis of steel structures [6-8]. A comparison among these models and that provided by Eurocode [9] is made as Figs. (3) and (4):

In Fig. (3), $f_{y T}$ and $f_{y 20}$ represent yield strength of structural steel at elevated temperature and room temperature. In Fig. (4), $E_{T}$ and $E_{20}$ respectively denote elastic modulus of structural steel at elevated temperature and room temperature. 
From the Fig. (3), it can be seen that there is visible difference among different research results about the yield strength of structural steel at elevated temperatures although the results of elastic modulus are similar, the reason is that there is no uniform standard to define the high-temperature yield strength internationally for no obvious yield limit and yield platform on the stress-strain curve of steel at high temperature. For example, EUROCODE 3 takes the stress which strain value $2.0 \%$ corresponds as yield strength, while reference [8] selected the yield strength according to the strain value $0.2 \%$.

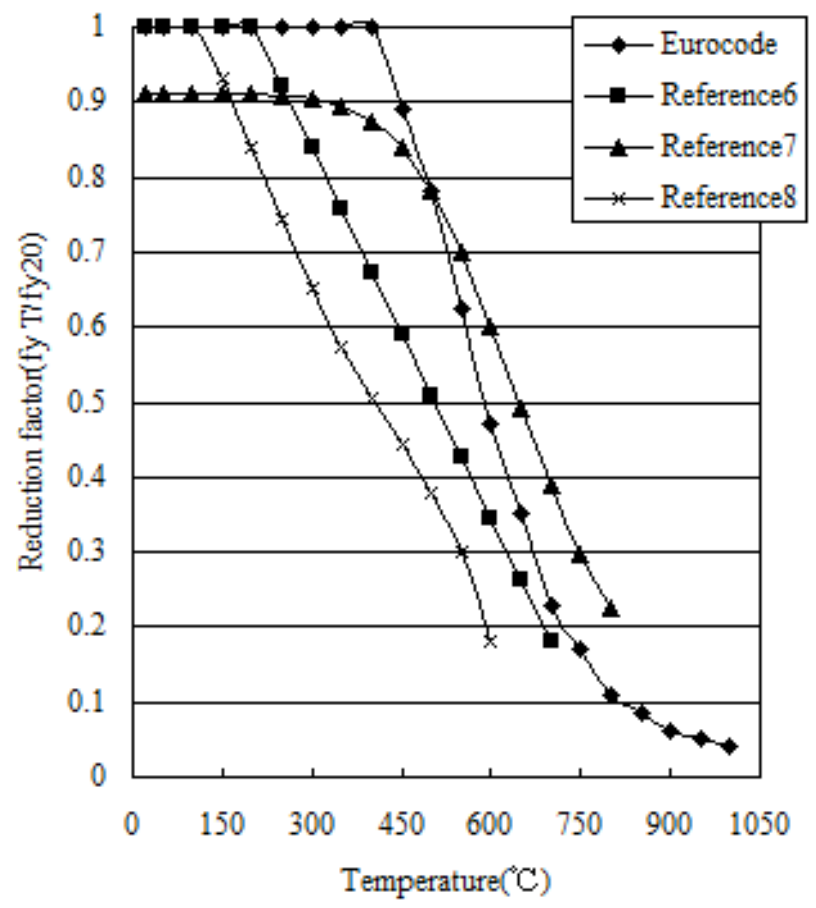

Fig. (3). Comparison of yield strength of structural steel at high temperatures.

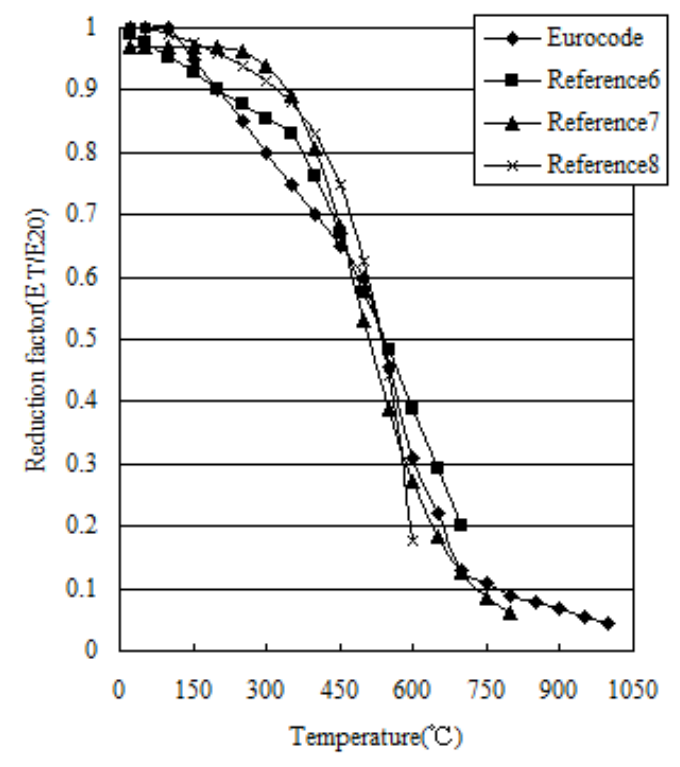

Fig. (4). Comparison of elastic modulus of structural steel at high temperatures.
The high-temperature tests mentioned above are all based on single path, which is other "transient state test" or "steady state test". "Transient state test" is the test in which the load applied to the specimen is kept constant while heating, while in "steady state test" the load is added with constant temperature. To take the effect of loading and heating paths into consideration, in 2002, a total of 25 tests about mechanical properties of structural steel at elevated temperatures were performed in Shanghai Jiao Tong University [10]. Threedimensional material models (a parametric equation of stress, strain and temperature) at different combinations of loading or unloading, heating or cooling were proposed. Two paths are taken as examples here, one is heating and loading path, the other is cooling and constant-load path. Their parametric equations of stress-strain-temperature relationship are expressed as equations 4 and 5 respectively, and the following (Figs. 5 and 6) show the simulative surface patch of the two equations in both paths.

$\sigma=f_{y}\left(2.357 \varepsilon / k_{t}\right)^{0.544}$

Where

$k_{t}=3.502+0.035(T-20)+1.009^{T-20}$

$\sigma=f_{y}\left(\frac{1.6 \times 10^{5} \varepsilon+6.294(400-T)^{2}}{8.516(400+0.934(400-T))}\right)^{0.224}$

The material models of different paths can be used to simulate the behavior of structures under real fire conditions. Because both the heating and cooling phase exist in a real fire, and meanwhile, an arbitrary point of a structural member may be at the state of loading or unloading, it is apparently unreasonable to make use of the same model for different situations.

\subsection{Fire Tests on Steel Structures and Structural Mem- bers}

In 1995, four tests on large-scale models of steel frames under different load levels and heating processes were performed in China for the first time [11]. All frames being tested were two-dimensional, one-storey and one-span unbraced portal frames and they were not protected against fire. During every test, the load applied on the frame kept constant while the temperature was increased by a speciallybuilt gas furnace, the changes in temperature and deflection of the frame were then constantly recorded from the beginning of every test. For more detailed information about these tests, reference [11] can be referred to.

Another three tests on one-storey and two-span steel frames with several beams protected by fire coatings were carried out in the following year [12]. In 1997, to investigate the behavior of plane steel frames with damage cumulation throughout the whole period of fire, three totally fireprotected plane frame models were tested [13]. As for fire test on structural members, several steel columns and steel beams were tested under fire conditions $[14,15]$. The material properties of fire-resistant steel at high temperatures were tested in reference [16], which also carried out experiments to study the behaviors of fire-resistant steel beams and columns under ISO Standard 834. 


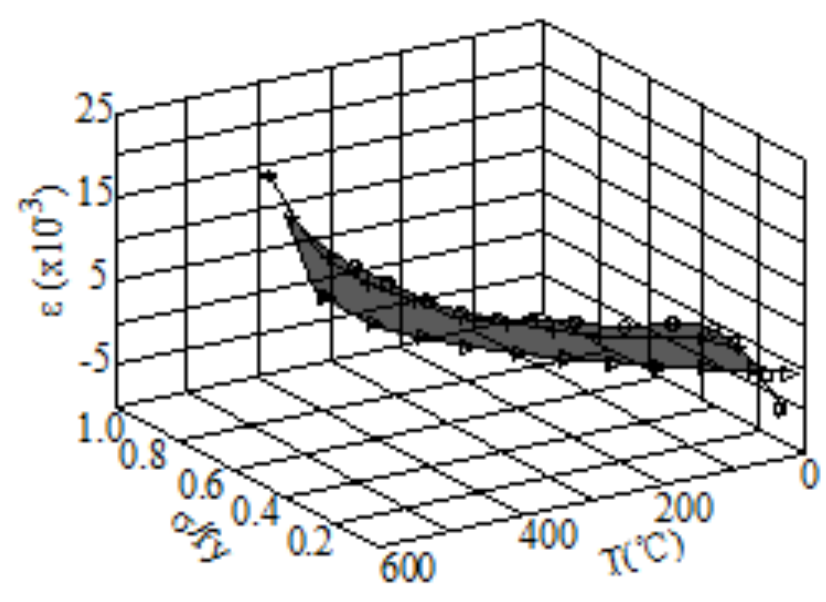

Fig. (5). The simulative surface patch of heating and loading path.

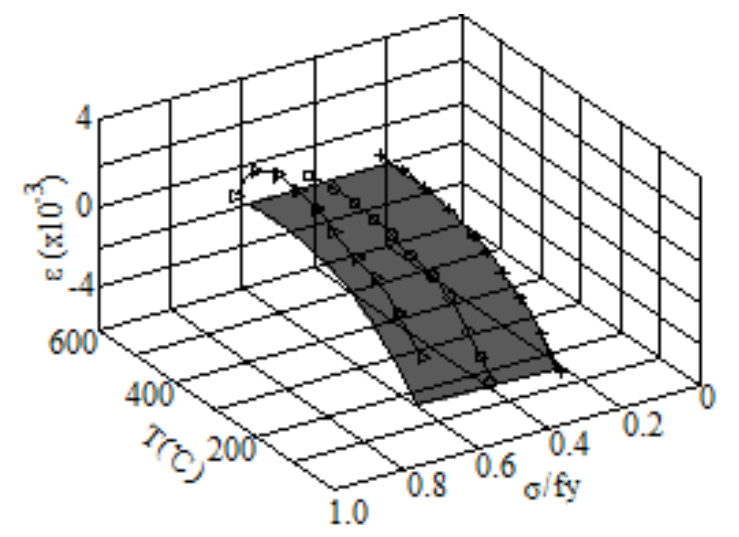

Fig. (6). The simulative surface patch of cooling and constant-load path.

To investigate the behavior and failure mode of restrained steel beams under fire conditions, reference [17] carried out tests in 2006. This reference studied the influence of axial restriction on steel beam and the effect of internal force on connections at both ends of the beam. The conclusion was drawn that the fire resistance property of restrained steel beams is stronger than that of generic simply supported beams. Besides these achievements, reference [18] and reference [19] carried out tests respectively to research the fire resistance behavior of $\mathrm{H}$-Shape steel beams and columns.

Although fire tests are time consuming and expensive, and sometimes, because of the difficulty of test control and data collection, test results may not be satisfactory, undoubtedly, the further experimental research is very important and necessary, it is greatly significant for investigation on the performance of steel structures under fire conditions. Only through tests, the real behavior of structures can be observed and the validity of a proposed analytical method can be checked.

\subsection{Finite Element Analysis of Steel Structures and Structural Members}

A lot of theoretical research works on fire resistance behavior of steel structures and steel members has been done during last decade. In the analysis, finite element method is widely adopted, and this pattern is likely to be continued. In reference [20], a direct iteration method for nonlinear analysis of plane steel frames in fire was presented. References [12] and [13] all dealt with finite element analysis of plane steel frames in fire conditions, and the latter took the effects of damage cumulation into consideration. And the fire resistance behaviors of large space steel building were researched in reference [21].

To analyze the mechanical performance and distortion rule of the plane steel frames under fire conditions, a finite element routing process was compiled in reference [22]. Based on the virtual work principle, this reference developed the "thermal-inelastic" stiffness equation and the "thermal load" equation of plane steel frame under different stresstemperature path. Then nonlinear finite element analysis was carried out according to increment iteration method. During the analysis, the corresponding material behavior was used according to different stress-temperature paths, and the transition principle among different paths was taken into account. The element "thermal-inelastic" stiffness equation being presented by reference [22] is shown as equation 6 .

$\left[k_{\text {ine }}\right] \mathrm{d}\{d\}=\mathrm{d}\{f\}+\left\{\Delta R_{T}\right\}$

From mentioned above we can know that both equations supplied by the technical code (CECS 200: 2006) and nonlinear finite element methods can analyze the fire resistance behavior of steel structures. To study the difference among the results of different method s, a comparison was carried out in reference [23]. In this reference, the fire resistance behavior of a three-storey and three-span plane steel structure was analyzed using three different methods: calculative method according to CECS 200: 2006, finite element routing process presented by reference [22], and ANSYS finite element analytical program. Fig. (7) shows the computational model of the steel frame, the fire region can be seen in Fig. (7), three sides of the beam, except the top side, are in fire. The changing curves of mid-span deflection and internal axial force corresponding to temperatures of the heated beam are given in Figs. (8) and (9).

From the comparison of three computational results, the conclusion can be drawn that the mid-span deflections of the beam in fire are pretty much the same thing, especially when the temperature is below $500{ }^{\circ} \mathrm{C}$, while as to internal axial forces, method of technical code CECS is a little more conservative than the other two methods. But on the whole, the trend of frame behavior changing with temperatures is uniform.

Besides the researches on high-temperature behaviors of steel material and steel structures, the fire resistance of beam-to-column joints and steel-concrete composite structures has also been investigated and some achievements have been obtained in China.

\subsection{Fire Resistance of Beam-to-Column Joints}

Reference [24] analyzed the temperature elevating of steel connections using finite element method, meanwhile the tests were carried out to validate the theoretical results, and the experience equation to compute the temperature of steel connections according to test results was acquired. The 
fire resistance behavior of high-strength bolted connections for steel structures was studied in reference [25], during the study, the finite element method was used and brick elements were adopted. A program was developed considering both the material and the geometrical nonlinearity. And based on a large number of parameters analysis, the practical equations for calculating the limit temperature of the highstrength bolted connection under fire were proposed in this reference. To investigate the behavior of $\mathrm{H}$-shape steel beams (end-plate connection) under fire, reference [26] carried out tests in 2006. Except the steel connections, the high temperature performance of concrete filled steel tubular beam-to-column connections had also been researched [27].

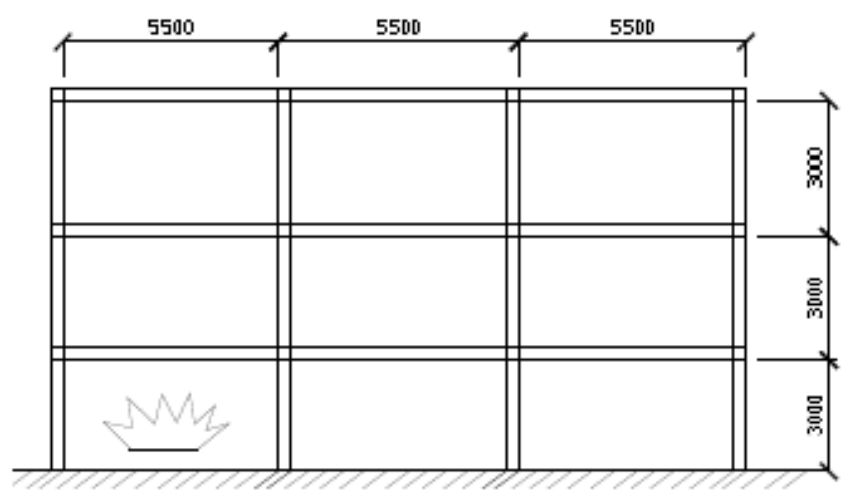

Fig. (7). The computational model of the steel frame.

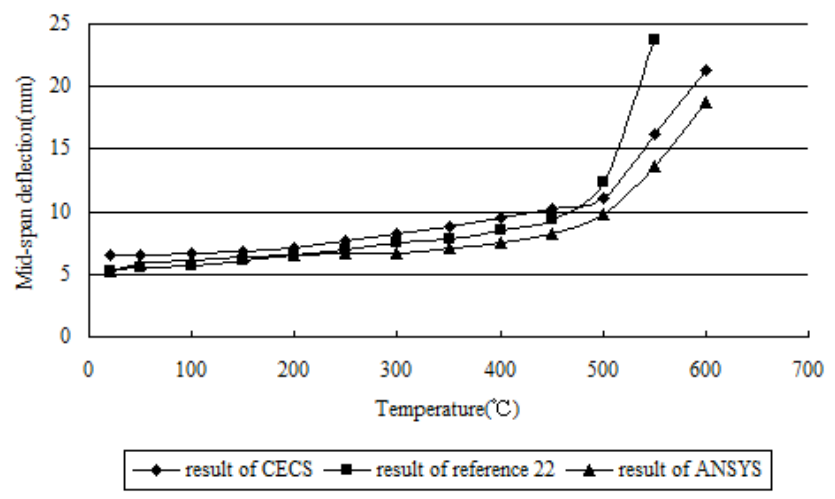

Fig. (8). Curves of mid-span deflection with temperature of beam in fire.

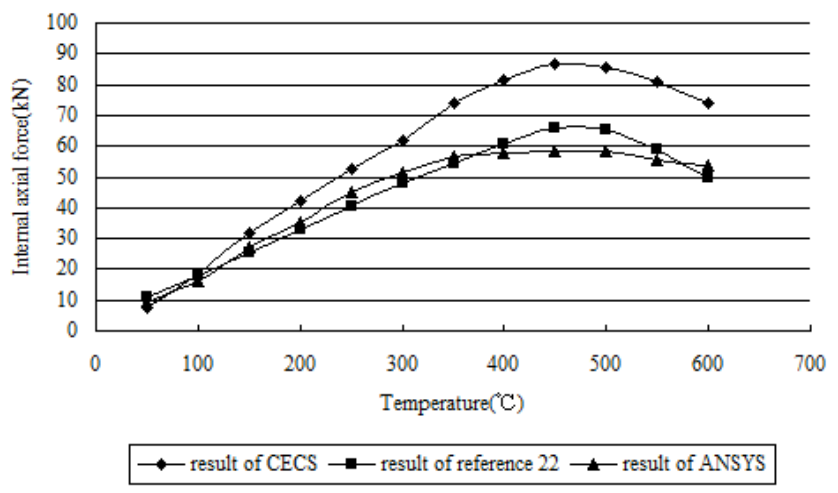

Fig. (9). Curves of internal axial force with temperature of beam in fire.

\subsection{Fire Resistance of Steel-Concrete Composite Struc-} tures

The researches on fire resistance of composite structures are not as many as those of steel structures, but there are still some productions being acquired.

The thermal properties and the stress-strain relations of steel and concrete in steel reinforced concrete columns under high temperature were determined in reference [28], finite element method was applied to calculate the temperature fields of the section. A numerical method was developed to calculate the fire resistance and the load-deformation curves of steel reinforced concrete columns, and the theoretical method was proved by tests. Based on the theoretical model, influences of the parameters on fire resistance behavior and bearing capacity were analyzed. A simplified model was developed for calculating the fire resistance of steel reinforced concrete columns.

Reference [29] studied the behavior of lightweight steelconcrete composite beams subjected to ISO Standard 834 . The fire region and the full curve of the members were calculated, the load resistance ratio was studied and the related factors about those subjects were also derived in this reference. To investigate the structural characteristics of steelconcrete composite floor system subjected to fire, theoretical analysis and experimental research had been carried out respectively in reference [30] and reference [31], the former established a nonlinear finite element equation and corresponding program to analyze the structural behavior of steelconcrete composite floors subjected to fire, and the latter tested four specimens which were composed of steel beams and steel profile deck-concrete composite slab, the results from theoretical analysis and experimental research were compared and they agreed with each other very well. With the finite element computation, theoretical analysis and experimental research, the fire-resistance behavior and bearingcapability mechanism of restrained composite beams were investigated in reference [32], the analysis method used in the whole temperature elevating process and the simplified calculation method being applied in practical design were also established in this reference.

It must be mentioned that the research achievements being referred to in this paper are only typical representations in the corresponding fields, there are still many other studies being carried out by many other researchers with regard to fire resistance of steel and composite structures in China.

\section{CONCLUSIONS}

From the above content, we can see that many works have been done on fire resistance design of steel structures in China, and the design method gets obvious development with the researches being carried out.

With the continuing increase of steel production and rapid development of economy in China, more and more structural steel buildings in various types will be constructed predicatively. For the fire resistance design of steel structures at the present time, traditional method according to ISO Standard 834 test on single member is widely used, although 
the concept of advanced method or performance-based method based on structural analysis has been introduced to practical design, a systematical calculation method for fire safety design of structural steel buildings has not been established. Both the research works and building codes or specifications regarding fire safety design have fallen behind the demands of practical engineering, further systematical researches still need to be carried out both theoretically and experimentally.

\section{ACKNOWLEDGEMENT}

The authors are grateful to the National Natural Science Foundation of China for the financial support.

\section{NOTATION}

$$
\begin{array}{ll}
T_{1} & =\text { Coating thickness to be calculated, in mm } \\
T_{2} & =\begin{array}{l}
\text { Coating thickness by ISO Standard } 834 \text { test, in } \\
\text { mm }
\end{array} \\
W_{1} & =\begin{array}{l}
\text { Weight of the structural steel member to be } \\
\text { insulated by coating, in } \mathrm{kg} / \mathrm{m}
\end{array} \\
W_{2} & =
\end{array}
$$

$\left[k_{0}\right]=$ Stiffness matrix for analysis without considering geometrical nonlinearity

$\left[k_{L}\right]=$ Stiffness matrix aroused by initial displacement

$\left[k_{\sigma}\right]=$ Stiffness matrix aroused by initial stress

$\left\{\Delta R_{T}\right\}=$ Equivalent thermal load

\section{REFERENCES}

[1] GB50016-2006, Building Code for Fire Protection Design. China planning press, Beijing, 2006.

[2] GB 50045-95, Code for Fire Protection Design of Tall Buildings. China planning press: Beijing, 2005.

[3] JGJ 99-98, Technical Specification for Steel Structure of Tall Buildings, China Architecture \& Building Press: Beijing, 2006.

[4] CECS 24: 90, Technical Specification for Application of Fire Protection Coating for Steel Structure, China planning press: Beijing, 1990.

[5] CECS 200: 2006, Technical Code for Fire Safety of Steel Structure in Buildings, China planning press: Beijing, 2006.

[6] Z. D. Lu, "Fire Response of RC Beams", Ph. D. thesis, Tongji University, Shanghai, P. R. China, 1989.

[7] T. G. Lv, "Experimental Investigation of Strength and Deformation of Reinforcing Bars Under High Temperature", M. D. thesis, Tsinghua University, Beijing, P. R. China, 1996.

[8] W. Tan, "Material Property of Structural Steel at High Temperature and Fire Response of Steel Frames", M. D. thesis, Tongji University Shanghai, P. R. China, 1998.

[9] NEN-EN 1993-1-2, Eurocode 3: Design of Steel Structures-Part 12: General Rules-Structural Fire Design, European Committee for Standardization: Brussels, 2005.

[10] Y. Xu, "Material Property of Structural Steel at Different StressTemperature Path and Structural Analysis of Steel Frames Under Fire", M. D. thesis, Shanghai Jiaotong University, Shanghai, P. R. China, 2003.

[11] J. C. Zhao and Z. Y. Shen, "Experimental studies of the behavior of unprotected steel frames in fire", Journal of Constructional Steel Research, vol. 50, pp. 137-150, 1999.

[12] S. C. Jiang, "Fire Resistance Analysis of Steel Frames", M. D. thesis, Tongji University, Shanghai, P. R. China, 1997.

[13] W. X. Cao, "Structural Analysis of Steel Frames Under Fire and Damage Cumulation", Ph. D. thesis, Tongji University, Shanghai, P. R. China, 1998.

[14] G. Q. Li, J. L. He and S. C. Jiang, "Fire resistance experiments and theoretical calculations of steel columns", China Building Structure, vol. 30, pp. 12-15, 2000.

[15] G. Q. Li, J. L. He and S. C. Jiang, "Fire resistance experiments and theoretical calculations of restricted steel beams", China Civil Engineering Journal, vol. 33, pp. 23-26, 2000.

[16] L. X. Lu, "Some Questions' Study about Design Based Performance of Steel-Structure in Fire", Ph. D. thesis, Tongji University, Shanghai, P. R. China, 2007.

[17] S. X. Guo, "The Behaviour of Restrained Steel Beam During Heating and Cooling and the Damage of Beam-to-Column Connection", $\mathrm{Ph}$. D. thesis, Tongji University, Shanghai, P. R. China, 2006.

[18] S. P. Cong, "Experimental Investigation of Behavior of H-Shape Steel Beams under Fire", M. D. thesis, Qingdao Institute of Architecture and Engineering, Qingdao, P. R. China, 2004.

[19] J. L. Lv, "Experimental Investigation of Behavior of H-Shape Steel Columns Under Fire", M. D. thesis, Qingdao Institute of Architecture and Engineering, Qingdao, P. R. China, 2004.

[20] J. C. Zhao, "Application of the direct iteration method for nonlinear analysis of steel frames in fire", Fire Safety Journal, vol. 35, pp. $241-255,2000$

[21] J. Q. Huang, "The Fire Protection Study of Planar Steel Structures in Large Space Building", Ph. D. thesis, Tongji University, Shanghai, P. R. China, 2006.

[22] L. W. Li, "Nonlinear Analysis of Fire Response of Plane Steel Frames under Different Stress-Temperature Paths", M. D. thesis, Shanghai Jiaotong University, Shanghai, P. R. China, 2005.

[23] D. Dai, "Material Properties of Steel at High Temperatures and its Application to Structural Analysis of Steel Frame under Fire Condition", M. D. thesis, Shanghai Jiaotong University, Shanghai, P. R. China, 2007. 
[24] W. Y. Wang, Y. L. Dong and K. Q. Yu, "Experimental Study and Analysis of the Temperature on Steel Connections in Fire", Journal of Qingdao Technology University, vol. 27, pp. 31-34, 2006.

[25] G. Q. Li and Y. Z. Yin, "Fire-resistant behavior of high-strength bolted connections for steel structures", China Civil Engineering Journal, vol. 36, pp. 18-25, 2003.

[26] X. D. Li, Y. L. Dong and S. P. Cong, "Experimental investigation of behavior of H-section steel beams (End-Plate Connection) under fire", Journal of Harbin Institute of Technology, vol. 38, pp. 978981, 2006

[27] Z. Tao, L. H. Han and Y. C. Wang, "Several key issues in the performance of connections to concrete filled steel tubular beamcolumns in fire condition", Steel Construction, vol. 20, pp. 91-94, 2005.

[28] Y. Q. Zheng and L. H. Han, "Fire performance and design method of steel reinforced concrete (SRC) columns", Progress in Steel Building Structures, vol. 8, pp. 22-29, 2006.
[29] X. Y. Mao and Y. Xiao, "Behavior of lightweight steel-concrete composite beams subjected to standard fire", Journal of Hunan University (Natural Sciences), vol. 32, pp. 64-70, 2005.

[30] S. C. Jiang, G. Q. Li, G. B. Lou and Y. J. Sun, "Numerical approach of behavior of steel-concrete composite slabs subjected to fire", China Journal of Building Structure, vol. 25, pp. 38-44, 2004.

[31] S. C. Jiang, G. Q. Li, H. Y. Zhou and Q. Wang, "Experimental study of behavior of steel-concrete composite slabs subjected to fire", China Journal of Building Structure, vol. 25, pp. 45-50, 2004 .

[32] Y. Z. Wang, "Behavior and Design of Composite Beam in Fire with Considering Global Structure Effect", Ph. D. thesis, Tongji University, Shanghai, P. R. China, 2006.

(C) Zhao and Yang; Licensee Bentham Open.

This is an open access article licensed under the terms of the Creative Commons Attribution Non-Commercial License (http://creativecommons.org/licenses/by-nc/3.0/) which permits unrestricted, non-commercial use, distribution and reproduction in any medium, provided the work is properly cited. 